\title{
Unfolded protein response in rice (Oryza sativa L.) varieties with different level of salt stress tolerance
}

\author{
Galang Rizki Ramadhan ${ }^{1,4}$, Sholeh Avivi ${ }^{2,4}$, Bambang Sugiharto ${ }^{3,4}$, and Wahyu Indra Duwi Fanata ${ }^{2,4, *}$ \\ ${ }^{1}$ Department of Biotechnology Graduate School Program University of Jember, Jl. Kalimantan Tegalboto, Jember, Jawa Timur 68121, \\ Indonesia \\ ${ }^{2}$ Department of Agrotechnology Faculty of Agriculture University of Jember, Jl. Kalimantan Tegalboto, Jember, Jawa Timur 68121, \\ Indonesia \\ ${ }^{3}$ Department of Biology Faculty of Mathematic and Natural Science University of Jember, J. Kalimantan Tegalboto, Jember, Jawa Timur \\ 68121, Indonesia \\ ${ }^{4}$ Center for Development of Advanced Science and Technology (CDAST) University of Jember, J. Kalimantan Tegalboto, Jember, Jawa \\ Timur 68121, Indonesia \\ *Corresponding author: wahyuindra.faperta@unej.ac.id
}

SUBMITTED 25 June 2021 REVISED 22 July 2021 ACCEPTED 25 July 2021

\begin{abstract}
Plants activate the unfolded protein response as part of cellular adaptation, thereby maintaining the endoplasmic reticulum homeostasis during external stresses exposure. In this study, we examined the relationship between the degree of salt tolerance and unfolded protein response-related gene expression in India salt-tolerant Pokkali and INPARI 35 varieties compared to the Indica salt-sensitive counterpart IR64 and INPARI 4 varieties. Our result showed that the salt tolerance of Pokkali and INPARI 35 had been confirmed by their higher survival rate, higher chlorophyll content, lower electrolyte leakage, and lower $\mathrm{H} 2 \mathrm{O} 2$ and malondialdehyde content under salt stress conditions. Furthermore, the expression of unfolded protein response genes was highest in INPARI 35, whereas IR64 and INPARI 4 exhibited low gene induction during endoplasmic reticulum stress conditions. Among the four examined varieties the salt tolerant Pokkali surprisingly showed the lowest induction of all examined unfolded protein response-related genes. These results indicated the possibility that unfolded protein response supports the rice plant for adapting to the saline environment.
\end{abstract}

KEYWORDS Rice; salinity stress; endoplasmic reticulum stress; unfolded protein response; gene expression

\section{Introduction}

Soil salinity has become one of the major constraints that negatively affect rice productivity worldwide. As the glycophyte cereal plant, rice generally exhibits low adaptability against high concentrations of $\mathrm{NaCl}$ that present in the rhizosphere area. Salinity stress occurs when the concentration of sodium $\left(\mathrm{Na}^{+}\right)$and chloride $\left(\mathrm{Cl}^{-}\right)$ions in the soil solution exceeds the tolerable limit of rice. Salt stress affects the physiology and biochemistry processes of rice by given water stress, disturbs ion homeostasis, nutritional disorders, alteration of metabolic processes, oxidative stress, reduction of growth and cell division, and membrane disorganization (Ya'acob et al. 2017).

Rice that are grown under high salinity conditions experience both osmotic and ionic stresses. Osmotic stress occurs when the concentration of $\mathrm{Na}+$ is high in the roots. High concentration $\mathrm{NaCl}$ in the soil solution leads to the decreased concentration of potassium $\left(\mathrm{K}^{+}\right)$, displacement by $\mathrm{Na}^{+}$, depolarization of cell membrane. The decrease of $\mathrm{K}+$ also caused decreased turgor cell and stomata closure (Ragel et al. 2019). Rice has several mechanisms to respond the stress including, the accumulation of osmoprotectant compounds, ion homeostasis, reactive oxygen species (ROS) detoxification, and activated several genes to maintain the balance of physiological processes of the cells (Hoang et al. 2016). A previous study reported an increased ROS production in rice plants was mediated by a specific gene in response to high extracellular $\mathrm{NaCl}$ concentration (Laohavisit et al. 2013).

Endoplasmic reticulum (ER) is responsible for synthesizing half of eukaryotes protein, but its function is easily disrupted when the cells are exposed to unfavorable environments. The disturbed ER function leads to the accumulation of misfolded and unfolded protein in the lumen, which subsequently generates the condition commonly termed as ER stress. In order to re-establish ER homeostasis, plant activated unfolded protein response (UPR) by increase protein folding capacity through the up regulation of a subset genes encoding the ER-localized chaper- 
one protein and degrading misfolded proteins by triggering the ER-associated protein degradation (ERAD) mechanism (Liu and Howell 2016; Fanata et al. 2013). In rice, OsbZIP39 and OsbZIP74 transcription factors play a pivotal role in UPR activation. ER stress activates both transcription factors through ER to nucleus relocation by proteolytical cleavage of OsbZIP39 and OsbZIP74 mRNA unconventional splicing resulting in up-regulation of several ER chaperones such as BiP1, PDIL1-1, Calnexin, and Calreticulin (Lu et al. 2012; Takahashi et al. 2012).

Our experiment used two salt tolerant rice varieties, Pokkali and INPARI 35, altogether with IR64 and INPARI 4 as sensitive varieties to investigate the relationship between salinity stress tolerance and UPR induction level. The salt tolerance level and expression of ER chaperone genes in each variety have been analyzed through phenotypic, biochemical, and molecular methods.

\section{Materials and Methods}

\subsection{Plant material and growing condition}

The seedling of INPARI 35, Pokkali, INPARI 4, and IR64 rice were used in this study. Pokkali and INPARI 35 are classified as potential rice tolerance varieties, while INPARI 4 and IR64 are salt stress susceptible varieties (Kumari et al. 2018; ?). Rice seeds were imbibed in the water for three days and twenty germinated rice seeds of each variety were planted in pots containing natural soil. The plants were grown for two weeks in a greenhouse with 28-32 ${ }^{\circ} \mathrm{C}$ temperature under natural sunlight exposure and daily irrigated by submerging the three-fourths of the pots into the water.

\subsection{Salt Tolerance Analysis}

Salt tolerance analysis was conducted by soaking the pots of 2-week-old rice seedling into $100 \mathrm{mM} \mathrm{NaCl}$ for six days. The salt tolerance of each rice variety was manifested by the survival rate at the six days of salt stress treatment by counting the percentage of living plants over the total population of the seedling.

\subsection{Relative Electrolyte Leakage}

Electrolyte leakage ratio was measured according to Ueda et al. (2013). The leaves of salt stress- and non-treated seedling were cut into $0.5-1 \mathrm{~cm}$ length and $0.5 \mathrm{~g}$ of small cute leaves were gently shaken in $20 \mathrm{~mL}$ distilled water in flat bottomed Makarthy tube for $24 \mathrm{~h}$ at room temperature. Electrolyte conductivity of the water was measured using a conductivity meter (Horiba Scientific) and the result was expressed as EC1. The tubes containing mixture water and leaves were autoclaved at $120^{\circ} \mathrm{C}$ for $15 \mathrm{~min}$, and the electrolyte conductivity of cooled water was measured to obtain the total electrolyte conductivity (EC2). Relative electrolyte leakage was counted using the formula: EC1/EC2 $\times 100 \%$.

\subsection{Total Chlorophyll}

Total chlorophyll was measured according to the method of Arnon (2018); Ma et al. (2018) with modification. Two hundred milligram of small-cut fresh leaves were placed into $15 \mathrm{~mL}$ conical tube containing $10 \mathrm{~mL}$ absolute ethanol. The mixtures were gently agitated for $48 \mathrm{~h}$ at room temperature. Chlorophyll content was analyzed by measuring the OD value of ethanol solution using Hitachi $\mathrm{U}-2900$ spectrophotometer at $649 \mathrm{~nm}$ and $665 \mathrm{~nm}$. Total chlorophyll was expressed as $\mathrm{mg} \mathrm{g}^{-1}$ fresh weight.

\subsection{Hydrogen peroxide content}

Hidrogen peroxide content of salt stress treated rice was measured according to the method described by Velikova et al. (2000). Three hundred milligram of fresh leaves were ground and homogenized with $3 \mathrm{~mL}$ of $0.1 \%(\mathrm{v} / \mathrm{v})$ trichloroacetic acid. The homogenate was centrifuged at $12,000 \mathrm{rpm}$ for $15 \mathrm{~min}$ at $4{ }^{\circ} \mathrm{C}$, and the resulting supernatant was transferred into a new microtube. The reaction mixtures were subsequently made by mixing $0.5 \mathrm{~mL}$ supernatant, $0.5 \mathrm{~mL}$ of $50 \mathrm{mM}$ sodium phosphate buffer $(\mathrm{pH}$ 7.0) and $1 \mathrm{~mL}$ of $1 \mathrm{M}$ potassium iodide. Absorbance was measured at $390 \mathrm{~nm}$ and the hydrogen peroxide content was expressed as $\mu \mathrm{g} \mathrm{g}^{-1}$ fresh weight.

\subsection{Malondialdehyde Content}

Malondialdehyde (MDA) contents were measured according to the method described by Hodges et al. (1999). One hundred milligrams of fresh weight leaves from each stress treatment were ground and homogenized with $1 \mathrm{ml}$ of $0.1 \%(\mathrm{v} / \mathrm{v})$ trichloroacetic acid solution and centrifuged at $10,000 \mathrm{rpm}$ for $5 \mathrm{~min}$ at $4{ }^{\circ} \mathrm{C}$. Five hundred microliter of supernatant were mixed with $500 \mu \mathrm{L} 0.5 \%(\mathrm{w} / \mathrm{v}) \mathrm{TBA}$ in $20 \%$ TCA. The mixtures were reacted at $100^{\circ} \mathrm{C}$ for $30 \mathrm{~min}$ and then stopped by incubating the mixture in ice for 10 min. Mixtures were subsequently centrifuged at 10.000 rpm for $10 \mathrm{~min}$ at $4{ }^{\circ} \mathrm{C}$ and the resulting supernatants were used for MDA measurement using spectrophotometry at 532 dan $600 \mathrm{~nm}$. MDA content was calculated using an extinction coefficient $1.55 \times 10^{5} \mathrm{mM}-1 \mathrm{~cm}-1$ and expressed as $\mu \mathrm{Mg}^{-1}$ fresh weight.

\subsection{Total RNA Isolation and qPCR Analysis}

Total RNA was extracted from the leaves of the control and $5 \mathrm{mM}$ DTT treated seedling using RNAprep pure kit (Tiangen) following the manufacturer's instruction. One microgram of total RNA was used for cDNA synthesis using a Revertra Ace qPCR RT Kit (Toyobo). The qPCR was performed using the CFX96 ${ }^{\text {TM }}$ Real-Time PCR Detection System (Bio-Rad) and SsoFast EvaGreen Supermix (BioRad) and specific primer sets (Supplementary Table 1). OsActin1 was used as internal reference gen to evaluate the transcriptional abundance of the selected UPR genes.

\subsection{Statistical analysis}

Each experiment of this study consisted of three biological replicates, and the statistical analysis was performed using 
analysis of variance (ANOVA).

\section{Results and Discussion}

\subsection{The tolerance of rice against salt stress}

To investigate the level of salinity tolerance of IR 64, INPARI 4, Pokkali, and INPARI 35 rice varieties, two-weekold seedlings were subjected to salt stress treatment by soaking the growing media with $100 \mathrm{mM} \mathrm{NaCl}$. The tolerance level of each rice variety was represented as stress survival rate and total chlorophyll at six days of stress treatment. In our experimental condition, all seedlings of four rice varieties showed normal growth under nonstress conditions and growth reduction was obviously seen in $\mathrm{NaCl}$ treated seedlings (Figure 1a). Both Pokkali dan INPARI 35 showed the highest survival rate at $79.17 \%$ and $75.83 \%$, respectively, in saline conditions. IR 64 and INPARI 4 showed lower survival rates at $51.67 \%$ and $47.50 \%$, respectively (Figure $1 \mathrm{~b}$ ). The result above clearly showed that salinity tolerance of tolerant and sensitive varieties was significantly different.

The salt tolerance response of plants is usually shown by the higher chlorophyll content, which is related to the higher photosynthetic rate during salt stress (Solangi et al. 2016). To confirm the survival rate result, we analyzed the total chlorophyll content of seedlings under salinity and their membrane integrity using relative electrolyte leakage (REL) analysis. On the total chlorophyll content analysis, Pokkali and INPARI 35 varieties showed a slight decrease of chlorophyll content, whereas IR64 and INPARI 4 exhibited a dramatic decrease of total chlorophyll content compared to control (Figure 2). Furthermore, the REL analysis result showed that Pokkali and INPARI 35 exhibited a lower electrolyte leakage value of $30.72 \%$ and $27.18 \%$, respectively, which statistically were not different from the control treatment (Figure 3). On the other hand, we observed the two-fold increase of electrolyte leakage in IR 64 and INPARI 4 at $70.25 \%$ and $66.33 \%$, respectively, indicating $\mathrm{NaCl}$ treatment leading to severe membrane damage on both varieties. Therefore, these results confirm that seedlings of Pokkali and INPARI 35 showed higher vigor than IR 64 and INPARI 4 under salt stress exposure.

\subsection{Oxidative stress level during salt stress}

High accumulation of reactive oxygen species (ROS) during salt stress has induced oxidative damage of membrane lipids. To obtain the biochemical evidence for elucidating the different levels of salt tolerance on four tested rice varieties, we analyzed the oxidative stress level by measuring the $\mathrm{H}_{2} \mathrm{O}_{2}$ content and malondialdehyde (MDA) as the product of lipid peroxidation. Our data showed that salt stress has efficiently induced the production of $\mathrm{H}_{2} \mathrm{O}_{2}$ and MDA in all tested rice varieties and we noticed that the salt-sensitive IR 64 and INPARI 4 accumulate a higher level of and $\mathrm{H}_{2} \mathrm{O}_{2}$ and MDA than of Pokkali and INPARI 35 varieties. Compared to their respective control treatment, $\mathrm{H}_{2} \mathrm{O}_{2}$ accumulation in salt-treated IR 64 and IN-

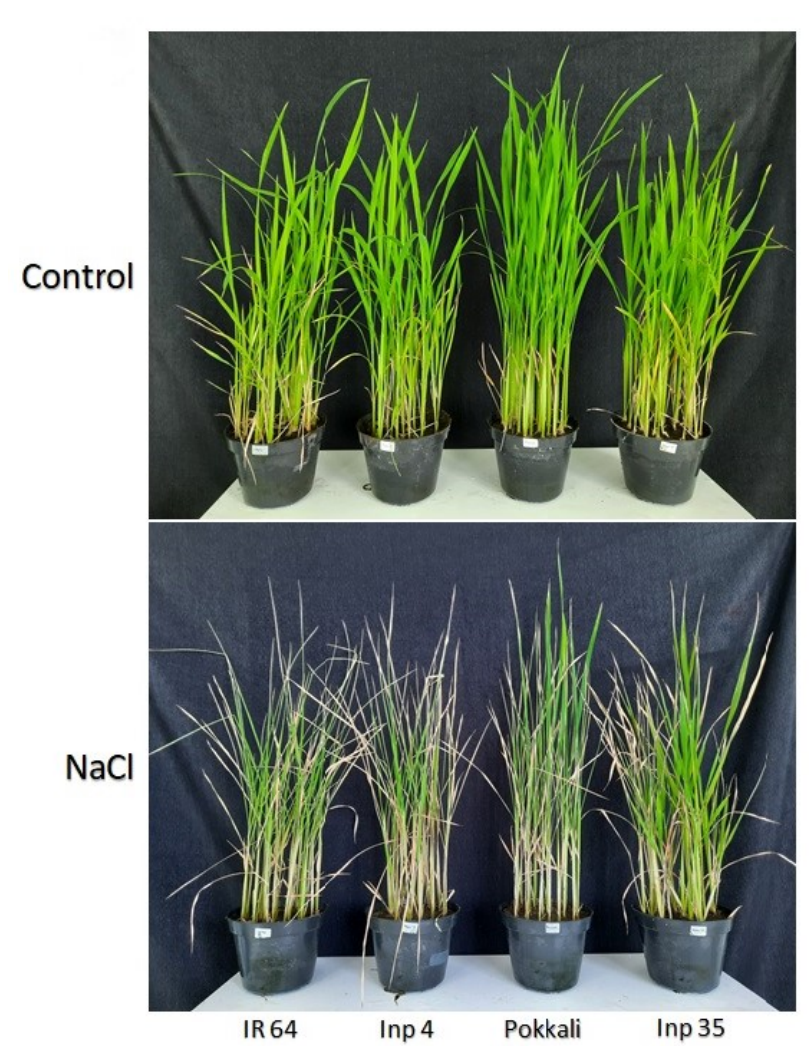

(a)

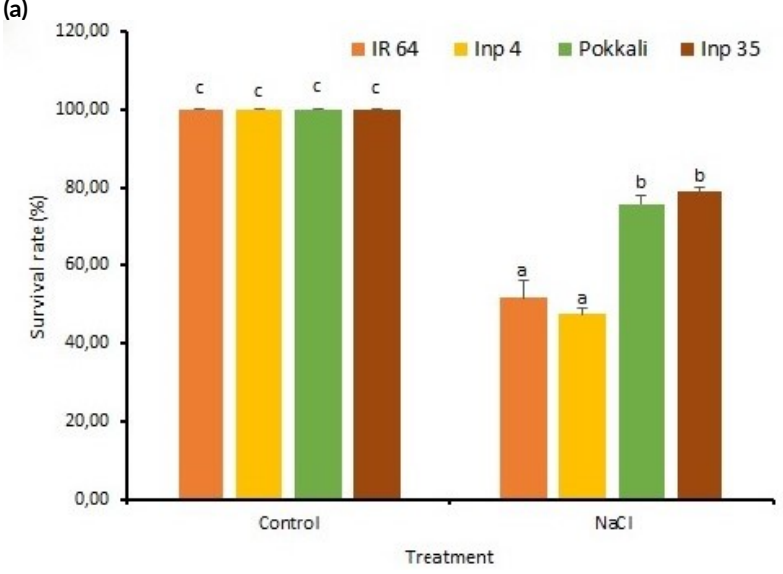

(b)

FIGURE 1 Effect of salinity stress on a) the phenotype and b) the survival rate of rice varieties IR64, INPARI 4, Pokkali, and INPARI 35 at 3 weeks seedling stage. Mean values of survival rate marked with the same letters do not differ significantly $(P \leq 0.05)$ in LSD. The vertical bar showed the mean $\pm S E(n=3)$.

PARI 4 were increased by 29- and 39-fold, respectively, whereas Pokkali and INPARI 35 showed lower $\mathrm{H}_{2} \mathrm{O}_{2}$ induction levels (18- and 16-fold, respectively) (Figure 4). Moreover, the MDH content in IR 64 and INPARI 4 was increased by $60.8 \%$ and $33.6 \%$, respectively, and Pokkali and INPARI 35 contained a lower induction level of MDH at $3.8 \%$ and $3.2 \%$, respectively (Figure 5). These results were in accordance with the previous studies that rice tolerance varieties to salinity stress have the lowest amount of ROS than the sensitive plant (Hoang et al. 2015). Therefore, these results confirm that salt stress-induced oxida- 


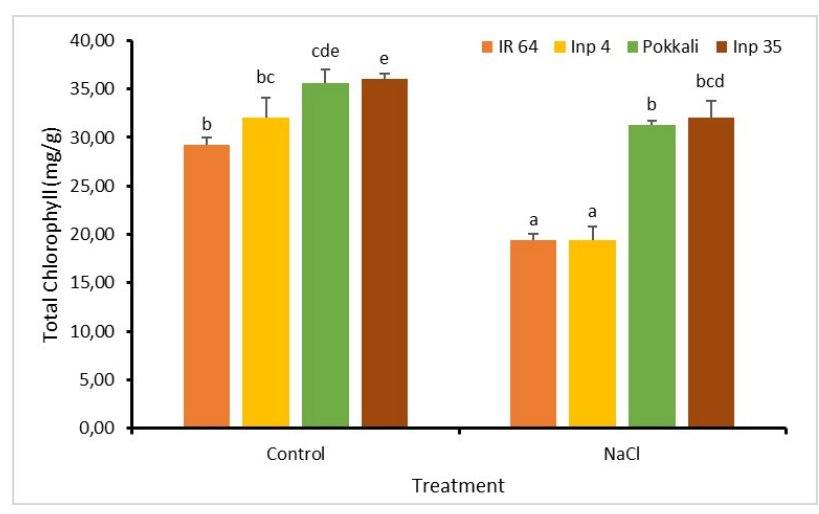

FIGURE 2 Effect salinity stress on the total chlorophyll rice varieties IR64, INPARI 4, Pokkali, and INPARI 35 at 3 weeks seedling stage. Mean values of total chlorophyll marked with the same letters do not differ significantly $(P \leq 0.05)$ in LSD. The vertical bar showed the mean $\pm S E(n=3)$.

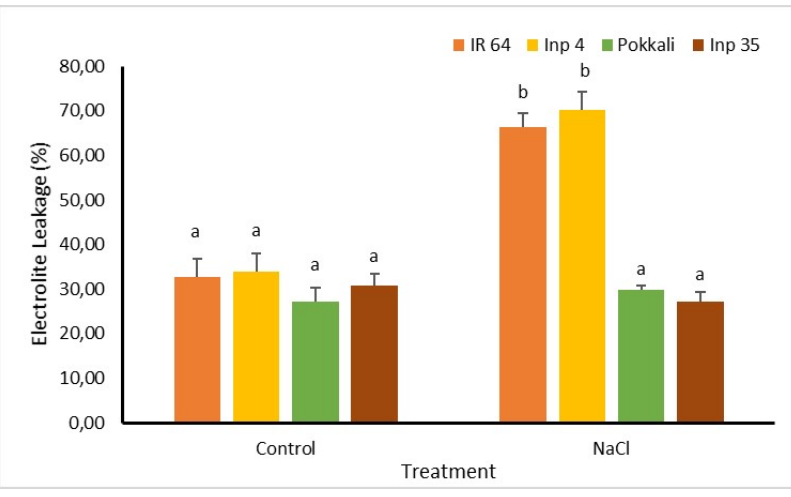

FIGURE 3 Effect salinity stress on the percentage of electrolyte leakage rice varieties IR64, INPARI 4, Pokkali, and INPARI 35 at 3 weeks seedling stage. Mean values of electrolyte leakage marked with the same letters do not differ significantly $(P \leq 0.05)$ in LSD. The vertical bar showed the mean $\pm S E(n=4)$.

tive stress was lower in salt-tolerant rice varieties but higher in the salt-sensitive counterparts.

\subsection{Activation of unfolded protein response by ER stress}

The phenotypical and biochemical results above have confirmed that Pokkali and INPARI 35 are categorized as salt tolerance varieties, whereas IR 64 and INPARI 4 are salt sensitive. To investigate whether the difference of salt tolerance in the tested rice correlates with the induction level of UPR, we analyzed the expression level of several ER stress-inducible genes in rice seedlings that experience ER stress induced by dithiothreitol (DTT). The induction levels of genes encoding ER-resident chaperone such as; binding immunoglobulin protein-1 (BiP1), binding immunoglobulin protein-2 (BiP2),calreticulin-2 (CRT2), protein disulfide isomerase-like 2-3 (PDIL2-3), and Calnexin (CNX) were analyzed by qPCR analysis. Our result showed that ER stress was efficiently induced by DTT, as shown by the up-regulation of all ER chaperone genes (Figure 6). Moreover, we found that the induction of ER chaperone genes was lower in salt-sensitive IR64 and

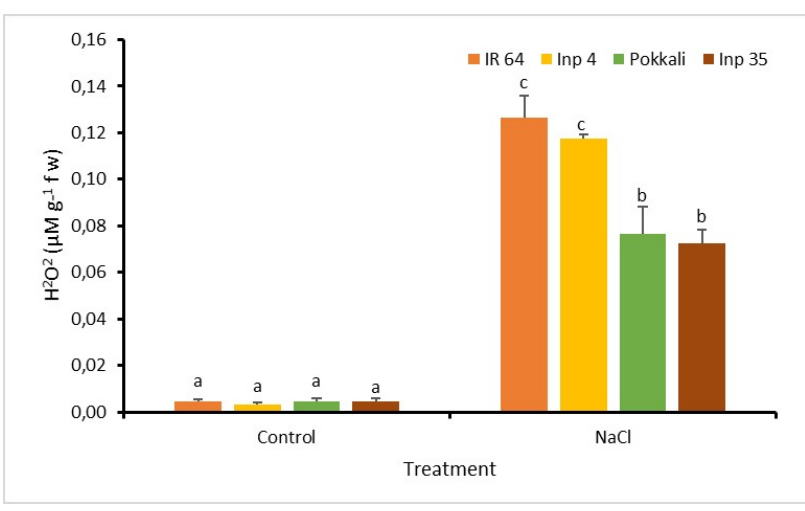

FIGURE 4 Effect salinity stress on the Hydrogen peroxide $\left(\mathrm{H}_{2} \mathrm{O}_{2}\right)$ content in IR64, INPARI 4, Pokkali, and INPARI 35 at 3 weeks seedling stage. Mean values of $\mathrm{H}_{2} \mathrm{O}_{2}$ content marked with the same letters do not differ significantly $(P \leq 0.05)$ in LSD. The vertical bar showed the mean $\pm S E(n=3)$.

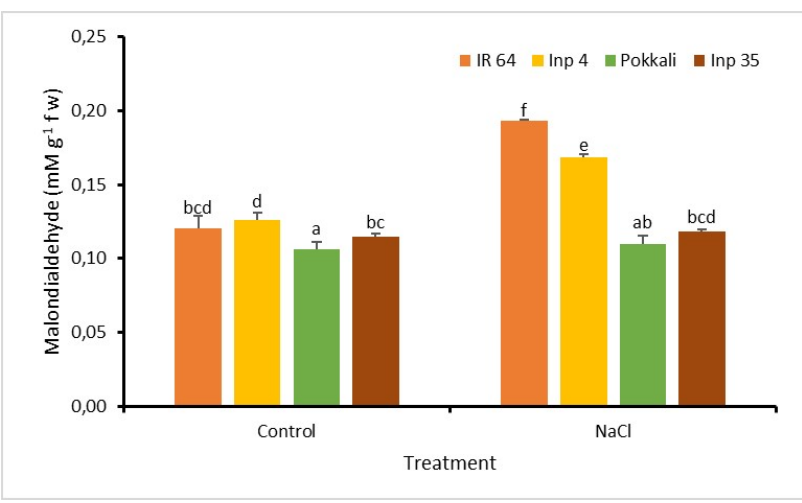

FIGURE 5 Effect salinity stress on the Malondialdehyde (MDA) in IR64, INPARI 4, Pokkali, and INPARI 35 at 3 weeks seedling stage. Mean values of MDA content marked with the same letters do not differ significantly $(P \leq 0.05)$ in LSD. The vertical bar showed the mean $\pm S E(n=3)$.

INPARI 4, whereas the salt-tolerant INPARI 35 showed the highest in the induction of BiP1, BiP2, PDIL2-3, and $C N X$. Interestingly, we observed the lowest induction of BiP2, CRT2, PDIL2-3, and CNX during the ER stress in salt-tolerant Pokkali rice and the basal level of BiP2 and CRT2 in Pokkali rice were also lowest among the tested varieties. These results indicate that UPR induction level correlates with the salt tolerance of IR 64, INPARI 4, and INPARI 35 but the salt tolerance of Pokkali rice has a minor correlation with the UPR activation.

\subsection{Discussion}

To investigate the correlation between UPR and salt tolerance level, we used Pokkali and INPARI 35 rice to represent salt-tolerant varieties and IR 64 and INPARI 4 for the salt-sensitive counterparts. The salt tolerance level of these four varieties was confirmed by the higher survival rate of Pokkali and INPARI 35 and lower survival rate of IR 64 and INPARI 4. Pokkali and INPARI 35 rice seedlings also showed a higher chlorophyll content compare to IR 64 and INPARI 4 under salt stress conditions. Moreover, REL analysis also showed that Pokkali 

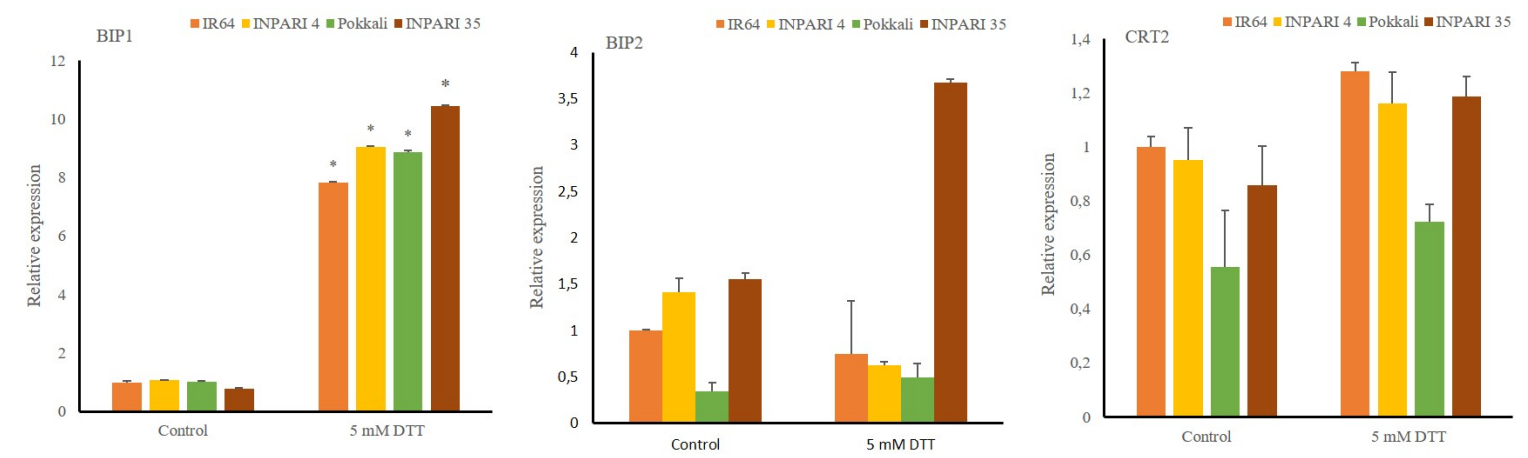

(a)

(b)

(c)
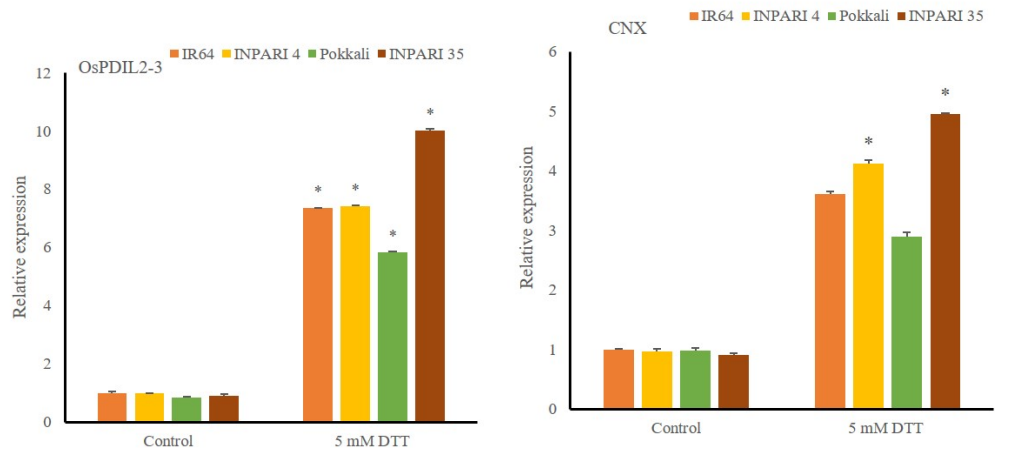

(d)

(e)

FIGURE 6 Relative expression of a) BiP1, b) BiP2, c) CRT2, d) OsPDIL2-3 and e) CNX compared to that of Actin1 detected by real-time qPCR. Values indicate relative expression levels in three biological replications from cDNA prepared from leaves. Vertical bars represent \pm SE.

and INPARI 35 have a higher capability to maintain their membrane integrity during salt stress. The high salt accumulation in the cell induces chlorosis, leaf burning, and electrolyte leakage, which are the phenotypic symptoms in plants at the initial stage of salinity stress (Rahman et al. 2016; do Amaral et al. 2020). The salt-tolerant rice grown under high salinity exhibited less pronounced chlorosis and electrolyte leakage (Ma et al. 2018; Tang et al. 2019).

The cell that accumulated a high concentration of $\mathrm{Na}^{+}$ generates more ROS that further contribute to the damage of cellular membrane (Ueda et al. 2013). Our result showed that $\mathrm{H}_{2} \mathrm{O}_{2}$ was highly accumulated in saltsensitive IR 64 and INPARI 4 varieties, contributing to the higher lipid peroxidation activity as manifested by high MDA content in these salt sensitive varieties. These data were in accordance with the result of Abdelgawad et al. (2016) that showed the high level of $\mathrm{H}_{2} \mathrm{O}_{2}$, MDA and electrolyte in maize seedling leakage as the response of salt stress treatment.

The obvious salt tolerance level in the four tested rice varieties has become the main investigation object to correlate the salt tolerance level with the UPR. The saltsensitive IR 64 and INPARI 4 showed the moderate activation of all tested genes under DTT-induced ER stress treatment. On the other hand, the salt-tolerant INPARI 35 showed the highest expression of BiP1, BiP2, PDIL23 , and $C N X$ among the tested varieties. The contrast re- sults were shown by the salt-tolerant Pokkali where BiP2, CRT2, PDIL2-3, and CNX were expressed at the lowest level. BiP1 is known as the abundant ER chaperone protein and OsPDIL2-3 also encodes a protein associated with protein folding and both genes were highly expressed under ER stress (Qian et al. 2015). It was also reported that rice overexpressed both $B i P 1$ and $C N X$ under ER stress conditions, but CNX expression is inversely related to BiP1 expression (Wakasa et al. 2011; Qian et al. 2015). Our result also showed that $C N X$ was expressed inversely to that of BiP1. Interestingly, Pokkali rice showed the lowest expression of CRT2 in both control and ER stress treatment. This result was in contrast to the positive function of calreticulin where the overexpression of wheat CRT in tobacco enhanced the drought and salt tolerance level (Xiang et al. 2015). Future investigation might be needed to deeply study the important roles CRT2 for salt tolerance, especially in other salt-tolerant rice varieties.

\section{Conclusions}

Our phenotypical and biochemical results confirmed that Pokkali and INPARI 35 are salt tolerant, whereas IR 64 and INPARI 4 are salt sensitive. The activation of unfolded protein response through up-regulation of ER chaperone genes might support the rice plant adaptation to the 
saline environment.

\section{Acknowledgments}

We would like to express our deep gratitude to the Ministry of Research, Technology and Higher Education of the Republic of Indonesia for providing financial assistance for this research in the form of Penelitian Tesis Magister research grant (974/UN25.3.1/LT/2020). We also thanks to Balai Besar Penelitian Tanaman Padi (BBPADI) for providing the rice seed materials that were used in this experiment.

\section{Authors' contributions}

GRR performed the experiment, collected the data, and analyzed data. SA, BS, WIDF designed the analysis, analyzed data. WIDF wrote the manuscript. All authors read and approved the final version of the manuscript. All authors read and approved the final version of the manuscript.

\section{Competing interests}

The author declare that they have no competing interest.

\section{References}

Abdelgawad H, Zinta G, Hegab MM, Pandey R, Asard H, Abuelsoud W. 2016. High salinity induces different oxidative stress and antioxidant responses in maize seedlings organs. Front Plant Sci. 7(MAR2016):111. doi:10.3389/fpls.2016.00276.

Arnon DI. 2018. Plant physiology. In: Encyclopedia of Ecology, volume 24. p. 549-557. doi:10.1016/B9780-12-409548-9.11130-3.

do Amaral MN, Arge LWP, Auler PA, Rossatto T, Milech C, de Magalhães AM, Braga EJB. 2020. Long-term transcriptional memory in rice plants submitted to salt shock. Planta 251(6):1-16. doi:10.1007/s00425-02003397-z.

Fanata WID, Lee SY, Lee KO. 2013. The unfolded protein response in plants: A fundamental adaptive cellular response to internal and external stresses. J Proteomics. 93:356-368. doi:10.1016/j.jprot.2013.04.023.

Hoang TM, Moghaddam L, Williams B, Khanna H, Dale J, Mundree SG. 2015. Development of salinity tolerance in rice by constitutive-overexpression of genes involved in the regulation of programmed cell death. Front Plant Sci. 6(March):1-14. doi:10.3389/fpls.2015.00175.

Hoang TML, Tran TN, Nguyen TKT, Williams B, Wurm P, Bellairs S, Mundree S. 2016. Improvement of salinity stress tolerance in rice: Challenges and opportunities. Agronomy. 6(4). doi:10.3390/agronomy6040054.
Hodges DM, DeLong JM, Forney CF, Prange RK. 1999. Improving the thiobarbituric acid-reactivesubstances assay for estimating lipid peroxidation in plant tissues containing anthocyanin and other interfering compounds. Planta. 207(4):604-611. doi:10.1007/s004250050524.

Kumari R, Kumar P, Sharma VK, Kumar H. 2018. Evaluation of Salinity Tolerance of Rice Varieties through in vitro Seed Germination and Seedling Growth. Int J Curr Microbiol Appl Sci. (7):2648-2659.

Laohavisit A, Richards SL, Shabala L, Chen C, Colaço RD, Swarbreck SM, Shaw E, Dark A, Shabala S, Shang Z, Davies JM. 2013. Salinity-induced calcium signaling and root adaptation in arabidopsis require the calcium regulatory protein annexin1. Plant Physiol. 163(1):253-262. doi:10.1104/pp.113.217810.

Liu JX, Howell SH. 2016. Managing the protein folding demands in the endoplasmic reticulum of plants. New Phytol. 211(2):418-428. doi:10.1111/nph.13915.

Lu SJ, Yang ZT, Sun L, Sun L, Song ZT, Liu JX. 2012. Conservation of IRE1-regulated bZIP74 mRNA unconventional splicing in rice (Oryza sativa L.) involved in ER stress responses. Mol Plant. 5(2):504514. doi:10.1093/mp/ssr115.

Ma NL, Che Lah WA, Kadir NA, Mustaqim M, Rahmat Z, Ahmad A, Lam SD, Ismail MR. 2018. Susceptibility and tolerance of rice crop to salt threat: Physiological and metabolic inspections. PLoS ONE. 13(2):1-17. doi:10.1371/journal.pone.0192732.

Qian D, Tian L, Qu L. 2015. Proteomic analysis of endoplasmic reticulum stress responses in rice seeds. Sci Rep. 5:1-15. doi:10.1038/srep14255.

Ragel P, Raddatz N, Leidi EO, Quintero FJ, Pardo JM. 2019. Regulation of $\mathrm{K}+$ nutrition in plants. Front Plant Sci. 10(March). doi:10.3389/fpls.2019.00281.

Rahman MA, Thomson MJ, Shah-E-Alam M, De Ocampo M, Egdane J, Ismail AM. 2016. Exploring novel genetic sources of salinity tolerance in rice through molecular and physiological characterization. Ann Bot. 117(6):1083-1097. doi:10.1093/aob/mcw030.

Solangi SB, Chachar Q, Chachar S, Solangi AB, Solangi JA, Solangi B. 2016. Effect of salinity $(\mathrm{NaCl})$ stress on physiological characteristics of rice (Oryza sativa L.) at early seedling stage. J Agric Technol. 12(2):263-279.

Takahashi H, Kawakatsu T, Wakasa Y, Hayashi S, Takaiwa F. 2012. A rice transmembrane bZIP transcription factor, OsbZIP39, regulates the endoplasmic reticulum stress response. Plant Cell Physiol. 53(1):144-153. doi:10.1093/pcp/pcr157.

Tang Y, Bao X, Zhi Y, Wu Q, Guo Y, Yin X, Zeng L, Li J, Zhang J, He W, Liu W, Wang Q, Jia C, Li Z, Liu K. 2019. Overexpression of a myb family gene, Osmyb6, increases drought and salinity stress tolerance in transgenic rice. Fronti Plant Sci. doi:10.3389/fpls.2019.00168.

Ueda A, Yahagi H, Fujikawa Y, Nagaoka T, Esaka M, Calcaño M, González MM, Hernández Martich JD, 
Saneoka H. 2013. Comparative physiological analysis of salinity tolerance in rice. Soil Sci Plant Nutr. 59(6):896-903. doi:10.1080/00380768.2013.842883.

Velikova V, Yordanov I, Edreva A. 2000. Oxidative stress and some antioxidant systems in acid rain-treated bean plants protective role of exogenous polyamines. Plant Sci. 151(1):59-66. doi:10.1016/S0168-9452(99)00197-1.

Wakasa Y, Yasuda H, Oono Y, Kawakatsu T, Hirose S, Takahashi H, Hayashi S, Yang L, Takaiwa F. 2011. Expression of er quality control-related genes in response to changes in BiP1 levels in developing rice endosperm. Plant J. 65(5):675-689. doi:10.1111/j.1365-313X.2010.04453.x.

Xiang Y, Hai Lu Y, Song M, Wang Y, Xu W, Wu L, Wang H, Ma Z. 2015. Overexpression of a triticum aestivum calreticulin gene (TaCRT1) improves salinity tolerance in tobacco. PLoS ONE. doi:10.1371/journal.pone.0140591.

Ya’acob NMA, Ismail M, Medina, Talarico TL, Casas IA, Chung TC, Dobrogosz WJ, Axelsson L, Lindgren SE, Dobrogosz WJ, et al. 2017. Salt Stress Tolerance in Rice: Emerging Role of Exogenous Phytoprotectants. Intech. 32:137-144. 